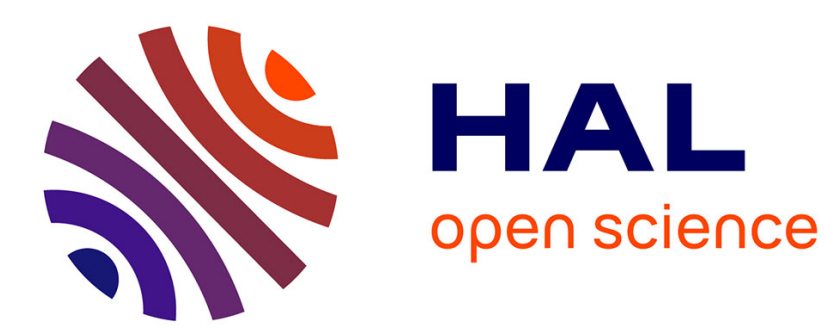

\title{
Matériaux semiconducteurs pour sources électroluminescentes et lasers
}

\author{
J. Lebailly
}

\section{To cite this version:}

J. Lebailly. Matériaux semiconducteurs pour sources électroluminescentes et lasers. Revue de Physique Appliquée, 1975, 10 (6), pp.364-364. 10.1051/rphysap:01975001006036400 . jpa-00243929

\section{HAL Id: jpa-00243929 https://hal.science/jpa-00243929}

Submitted on 1 Jan 1975

HAL is a multi-disciplinary open access archive for the deposit and dissemination of scientific research documents, whether they are published or not. The documents may come from teaching and research institutions in France or abroad, or from public or private research centers.
L'archive ouverte pluridisciplinaire HAL, est destinée au dépôt et à la diffusion de documents scientifiques de niveau recherche, publiés ou non, émanant des établissements d'enseignement et de recherche français ou étrangers, des laboratoires publics ou privés. 


\title{
MATÉRIAUX SEMICONDUCTEURS POUR SOURCES ÉLECTROLUMINESCENTES ET LASERS
}

\author{
J. LEBAILLY
}

R. T. C. La Radiotechnique, Compelec, 14000 Caen, France

\begin{abstract}
Résumé. - La première partie de l'exposé est consacrée à un rappel des mécanismes d'injection de porteurs minoritaires, de recombinaison radiative et des propriétés générales utilisées dans les sources électroluminescentes et lasers. L'on situe ensuite les ordres de grandeur des rendements quantiques obtenus actuellement avec les différents types de matériaux et de dispositifs.

Dans la seconde partie, l'on analyse plus particulièrement les paramètres concernant le matériau, qui interviennent dans les propriétés des dispositifs. A l'aide de plusieurs exemples pratiques (efficacités quantiques des transitions bande à bande dans $\mathrm{GaAs}_{1-x} \mathbf{P}_{x}$, des recombinaisons d'excitons liés à des centres isoélectroniques dans $\mathrm{GaP}$, efficacités de confinement des porteurs et des modes électromagnétiques dans les lasers au $\mathrm{Ga}_{1-x} \mathrm{Al}_{x} \mathrm{As}$ ), l'on mettra l'accent sur les moyens d'analyse des matériaux et leurs limitations.

La troisième partie de l'exposé concerne les axes d'étude actuels : différents mécanismes de dégradation des sources en fonctionnement et moyens de prévention correspondants ; hétérostructures ; utilisation de solutions solides (GaPAs, GaAlAs, GaInAs).
\end{abstract}

